\title{
Classification of the Micro, Small, Medium and Large (MSMLE's) Enterprises in Belize, Based on the Free Cash Flow (FCF)
}

Romaldo Isaac Lewis*

Faculty of Management and Social Science, University of Belize, USA

\begin{abstract}
The objective of this research was to classify the enterprises into Micro, Small, Medium \& Large (MSMLE's) in Belize base on its Free Cash Flow (FCF). The data that was used came from 1500 enterprises distributed within the nine municipalities through the country of Belize. The method that was used to classify the enterprises base on the Free Cash Flow was the Discriminant Analysis method. The specific objectives of this research were to 1) Evaluate the accuracy level in the classification of the enterprises in Belize. 2) Determine correlation level, or association of the contributing indicators or Factors, in the classification process, 3) Estimate a Mathematical Equation for Enterprise classification into MSMLE's for Belize. The study found that the Discriminant Analysis (DA) calculated four groups that can be classified as Micro, Small, Medium and Large Enterprises (MSMLE's). Additionally, it confirmed an accuracy level of $98.8 \%$. Furthermore, the calculated Mathematical Equation for unstandardized values is as follows:
\end{abstract}

$$
\mathrm{D} 1=-13.186+5.723 \mathrm{EBT}\left(\mathrm{X}_{1}\right)-0.258 \mathrm{BT}\left(\mathrm{X}_{2}\right)+0.013 \mathrm{GST}\left(\mathrm{X}_{3}\right)+6.954 \mathrm{NOPAT}(\mathrm{X} 4)+0.105 \mathrm{EI}(\mathrm{X} 5)
$$

Keywords: Free cash flow; MSMLE's; Taxes; Nopat; Belize; Discriminant analysis

\section{Introduction}

The main objective of this study was to classify the firms into Micro, Small, Medium and Large Enterprise (MSMLE's) with in the Belizean economy [1].

The study was concluded with the use of a Discriminant Analysis as an agglomeration procedure that determined the Discriminant Functions, Coefficients, and Association Level (\%), as well as the accuracy level of the selected cases or enterprises into its appropriate groups [2].

The study was based on the information of 1500 enterprises from the nine municipalities of the country. The sales and operational cost were then calculated to obtain the Earnings Before Interest \& Tax (EBIT). Additionally, the General Sales Tax (GST) and the Business Tax (BT) was deducted for the Earnings Before Interest \& Tax (EBIT), which then resulted in the Net Operating Profit after Tax (NOPAT). Nopat was then used to subtract the reinvestment to get to the Free Cash Flow (FCF).

\section{Literature Review}

Free Cash Flow (FCF) can be describe in financial terms as the monies that results from the subtraction of any reinvestment for the Net Operating profit after Tax (Nopat). Nopat as a financial term eliminates completely the influences of taxes since this can increase or decrease the performance of the Free Cash Flow [3].

Meena \& Pawan mentioned that the Discriminant Analysis (DA) can be classified as a technique that is been used when analysing data that is been categorized on some criteria or dependent variable.

For other authors, this technique is been view as a method to discriminate between two or more mutually exclusive and exhaustive groups on the basis of some explanatory variables $[4,5]$.

Additionally, the Discriminant Analysis as a process to assess the capacity of the variables to predict the classification of firms or groups within cluster since the analysis also creates an equation which will minimize the possibility of misclassifying cases into their respective groups or categories. Finally, a predicated group membership will always perform to reconfirm the accuracy or association level of the cluster groups into membership groups [6,7].

The Discriminant Analysis main purpose are to 1) To maximally separate the groups, 2) To determine the most parsimonious way to separate groups, and 3) To discard variables that are little related to group distinctions. However, researchers are always interested in the relationship between a group of independent variables and one categorical variable.

In today's world of investment portfolio, the Free Cash Flow is a modern practical terminology used to indicate, classify or identify the liquidity of an enterprise, especially for turnover reasons. Therefore, authors indicated that researcher would also like to know how many dimensions are needed to express the relationship $[8,9]$. By the use of this relationship, we can predict classification based on independent variables or assess how the independent variables separate the categorifies in the classification.

\section{Hypothesis}

\section{Null hypothesis}

1. There is no statistical significance in the effects caused by the financial indicators as well as the clusters $[8,10]$.

2. The accuracy level that results from the Discriminant Analysis is equivalent to $95 \%$ or more.

*Corresponding author: Romldo Isaac Lewis, Assistant Professor, Faculty of Management and Social Science, University of Belize, USA, Tel: 501-822-3680; E-mail: rlewis@ub.edu.bz

Received August 27, 2018; Accepted September 10, 2018; Published September 20, 2018

Citation: Lewis RI (2018) Classification of the Micro, Small, Medium and Large (MSMLE's) Enterprises in Belize, Based on the Free Cash Flow (FCF). J Bus Fin Aff 7: 350. doi: 10.4172/2167-0234.1000350

Copyright: (c) 2018 Lewis RI. This is an open-access article distributed under the terms of the Creative Commons Attribution License, which permits unrestricted use, distribution, and reproduction in any medium, provided the original author and source are credited. 


\section{Objectives}

\section{Specific objectives}

1. Evaluate the accuracy level in the classification of the enterprises in Belize [11].

2. Determine correlation level, or association of the contributing indicators or Factors, in the classification process [12].

3. Estimate a Mathematical Equation for Enterprise classification into MSMLE's for Belize [13].

\section{Methodology}

For this particular study a convenient stratified sample of 1500 enterprises were selected to participate in the process throughout the country of Belize, a number that is equivalent to an average of $15 \%$ of the population $(10,233)$ of registered enterprises in the nine municipalities in the country [14]. Information was taken from the enterprises that were registered during the last three fiscal years (April 1st, 2013 to March 31st, 2016).

In order to obtain a very high confidential level degree, 95\% was used and can be translated to the level of probabilistic success and $5 \%$ tolerance or failure as illustrates below [15]:

$$
\begin{aligned}
& =\left(\left(\mathrm{Z}^{2}\right)^{\star} \mathrm{P}^{\star} \mathrm{q}\right) /\left(\mathrm{e}^{2}\right) \\
& =\text { Provisional Sample size } \\
& \mathrm{Z}^{2}=\text { Abscissa of the normal curve }(1.96) \\
& \mathrm{P}=\text { Proportion within the population } \\
& \mathrm{q}=(1-\mathrm{p}) \\
& \mathrm{e}^{2}=\text { Precision level or variability } \\
& \mathrm{n}=\text { Sample size } \\
& \mathrm{n}=/((1+(/ \mathrm{N})) \\
& \mathrm{N}=\text { Number of enterprises }[16] .
\end{aligned}
$$

\section{Discriminant analysis as classification method}

The Discriminant Analysis was used as the classification method considering that is useful in determining whether a set of variables is effective in predicting category membership $[2,17]$. Additionally, its prediction equations are based on method that develops a multiple regression equation for each group, ignoring the discrete nature of these options let you specify where to store various row-wise statistics as observed in the table below.

\section{Results and Discussion}

\section{Group membership application}

Table 1 below, illustrates the summary of the classification process. The results indicated that 1500 data were processed, 0 data were missing or out of range, and 0 were at least was presenting as a discriminating variable [18].

The calculation of prior grouping was as calculated as part of the procedures as illustrated in table the analysis revealed the preclassification of four groups according to the Free Cash Flow (FCF). Based on a probability of $0.25 ; 1391$ cases were classified between the ranges of $\$ 1,569$ to $\$ 7,689,154,93$ were classified between the ranges of $\$ 7,689,155$ to $\$ 15,376,739,3$ were classified between the ranges of $\$ 15,376,740$ to $\$ 23,064,325$ and finally; 3 were classified between the ranges of $\$ 23,064,326$ to $\$ 30,751,911$ as expressed in the Table 2 .

\section{Verification of the accuracy of the clustering process}

To ensure that the cluster procedure was completed appropriately, a canonical discriminant analysis was performed on the four-cluster and the Six (6) variables. Three canonical discriminant functions were significant in deferring among the clusters $(\mathrm{p}<0.0005)$.

The analysis revealed that the discriminant functions had calculated Eigenvalues of 9.667, 0.674 and 0.053 ; with correlations of $0.95,0.635$ and 0.225 respectively. Such Eigenvalue can be classified as good, with a positive correlation nature for Function 1,2 and 3; the classification of the correlation level is Very High for Function 1, moderate for Function 2 and Low for Function 3. This correlation also indicates the high efficiency of the discriminant in discrimination [5,7]. Wilks' Lambda calculated a value of 0.053 for the first functions; 0.567 for the second function and finally; and 0.949 for the third function $(\mathrm{p}<$ 0.0005) as shown below Table 3 .

Table 4 below illustrates the information concerning the correlation between each of the discriminant variables and the Canonical Discriminant Function from a statistical standpoint. The highest correlation that resulted from the discriminating variables and the standardized discriminant function was the Net Operating Profit after Tax (NOPAT) $\left(\mathrm{X}_{4}\right)$ and the Earnings before Tax $(\mathrm{EBT})\left(\mathrm{X}_{1}\right)$ with values of 0.785 and 0.628 respectively for the first function.

With regards to the second function Business Tax $(\mathrm{BT})\left(\mathrm{X}_{2}\right)$ and General Sales Tax (GST)(X3) contribution calculated the correlation of 0.764 and 0.680 respectively. For the last function (3) the Business Tax (BT) $\left(\mathrm{X}_{2}\right)$ contributed to a correlation of 0.590 compared to the Earnings before Tax $(\mathrm{EBT})\left(\mathrm{X}_{1}\right)$ that calculated 0.209 . For a positive correlation this indicates the level of relationship that exists between discriminating variables and the standardized discriminant function.

To evaluate the effect of the individual discrimination of the variables; calculation was performed on the Standardized Canonical Discriminant Function Coefficients and the group centroid for the Standardized the Standardized Canonical Discriminant Function Coefficients and the group centroid for the Standardized Canonical Discriminant Function as express in the tables consecutively (Table 5).

\begin{tabular}{|c|c|c|}
\hline Cluster & cases & $\%$ \\
\hline 1 & 3 & $0.2 \%$ \\
\hline 2 & 8 & $0.5 \%$ \\
\hline 3 & 1470 & $98.0 \%$ \\
\hline 4 & 19 & $1.3 \%$ \\
\hline Valid & 1500 & $100 \%$ \\
\hline
\end{tabular}

Table 1: Classification processing summary.

\begin{tabular}{|c|c|c|c|}
\hline \multicolumn{4}{|c|}{ Prior Probabilities for Groups } \\
\hline $\begin{array}{c}\text { Free cash Flow (FCF) } \\
\text { Range? }\end{array}$ & Prior & \multicolumn{2}{|c|}{ Cases used in Analysis } \\
\cline { 3 - 4 } & Unweighted & Weighted \\
\hline 1569 TO 7689154 & 0.25 & 1391 & 1391 \\
\hline 7689155 TO 15376739 & 0.25 & 93 & 93 \\
\hline 15376740 TO 23064325 & 0.25 & 3 & 3 \\
\hline 23064326 TO 30751911 & 0.25 & 3 & 3 \\
\hline Total & 1 & 1490 & 1490 \\
\hline
\end{tabular}

Table 2: Prior probability for groups. 
Citation: Lewis RI (2018) Classification of the Micro, Small, Medium and Large (MSMLE's) Enterprises in Belize, Based on the Free Cash Flow (FCF). J Bus Fin Aff 7: 350. doi: 10.4172/2167-0234.1000350

Page 3 of 4

\begin{tabular}{|c|c|c|c|c|c|c|c|c|c|}
\hline \multicolumn{5}{|c|}{ Eigenvalues } & \multicolumn{5}{|c|}{ Wilk's Lambda } \\
\hline Function & Eigenvalue & Variance & Cumulative\% & Correlation & Function(S) & Lambda & Square & df & Sig. \\
\hline 1 & $9.667^{\mathrm{a}}$ & 93 & 93 & 0.952 & 1 through 3 & 0.053 & 4356.61 & 15 & 0 \\
\hline 2 & $.654^{\mathrm{a}}$ & 6.5 & 99.5 & 0.635 & 2 through 3 & 0.567 & 842.51 & 8 & 0 \\
\hline 3 & $0.053^{\mathrm{a}}$ & 0.5 & 100 & 0.225 & 3 & 0.949 & 77.23 & 3 & 0 \\
\hline
\end{tabular}

First 3 canonical discriminant functions were used in the analysis

Table 3: Eigenvalues and Wilks' lambda.

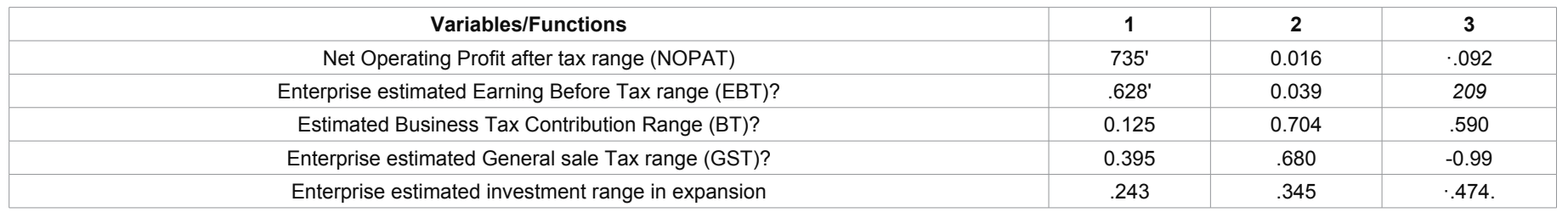

Table 4: Structure matrix.

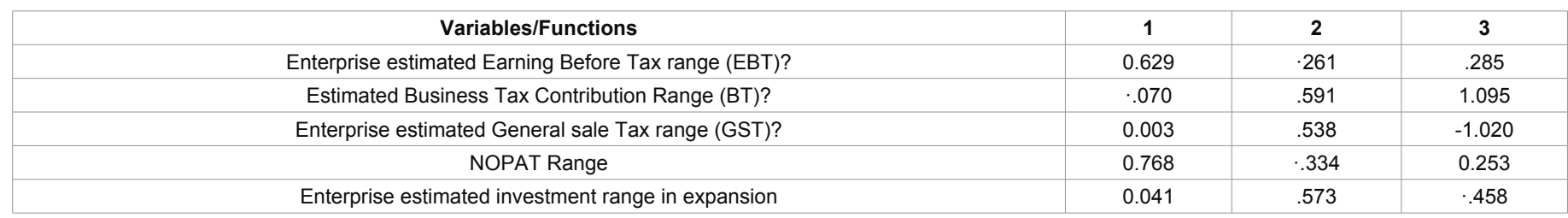

Table 5: Standardized canonical discriminant function coefficient.

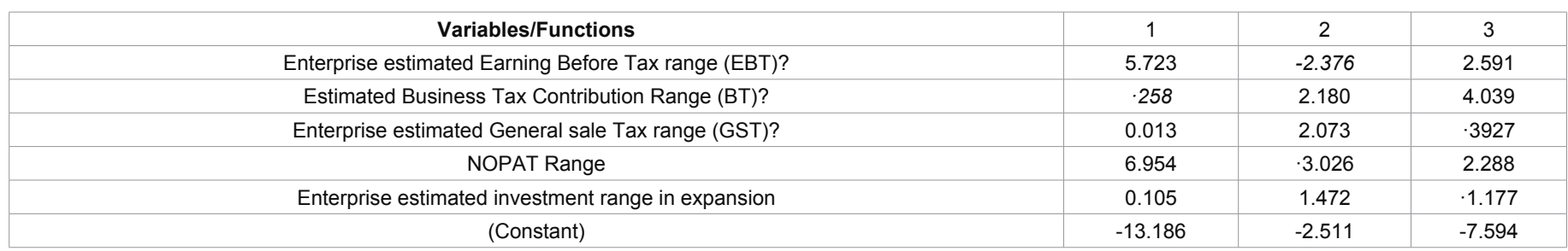

Table 6: Unstandardized canonical discriminant.

According to the calculated Standardized Canonical Discriminant Function Coefficients the most statistically significant function is the First one (1) according to its Eigenvalue (9.667) and the calculated the $\mathrm{Chi}^{2}$ value (4356.61). This indicates that the Discriminant Equation can be expressed for the standardize values as follows:

$\mathrm{D} 1=0.629 \mathrm{EBT}\left(\mathrm{X}_{1}\right)-0.070 \mathrm{BT}\left(\mathrm{X}_{2}\right)+0.003 \mathrm{GST}\left(\mathrm{X}_{3}\right)+0.768 \mathrm{NOPAT}($ $\mathrm{X} 4)+0.041 \mathrm{EI}(\mathrm{X} 5)$

The Unstandardized Canonical Discriminant Function Coefficients was also calculated here. In line with the above statistical significance, function number one was also used according to its Eigenvalues (9.667) and the calculated $\mathrm{Chi}^{2}$ value (4356.61). This measurement indicates that the Discriminant Equation can be expressed as the Unstandardized values as follows Table 6:

$\mathrm{D} 1=-13.186+5.723 \mathrm{EBT}\left(\mathrm{X}_{1}\right)-0.258 \mathrm{BT}\left(\mathrm{X}_{2}\right)+0.013 \mathrm{GST}\left(\mathrm{X}_{3}\right)+6.954 \mathrm{~N}$ OPAT(X4)+0.105EI(X5)

The correct prediction analysis revealed that $98.8 \%$ of the cases or enterprises were correctly classified into its corresponding group base on the ranges of the Free Cash Flow (FCF) compared to an insignificant $1.2 \%$ of the cases or Enterprises that weren't correctly classified as illustrated in Table 7.

In conclusion the Discriminant Analysis serves as a statistical procedure to verify and measure the level of accuracy of the cases classified within and among the groups based on the Free Cash Flow (FCF) ranges of the dependent variable as shown in the Table 7. It is also a representation of the proximity of the cases around the Group Centroid. Base on this calculation Hypothesis No. 2 is accepted, considering that the prediction of the clusters was higher than $95 \%$ as illustrated in the table below.

\section{Conclusion}

1. The discriminant Analysis (DA) calculated four groups that can be classified as Micro, Small, Medium and Large Enterprises (MSMLE's), with a confirmed accuracy level of $98.8 \%$.

2. The Mathematical Equation for Unstandardized values for Enterprise classification is as follows:

$\mathrm{D} 1=-13.186+5.723 \mathrm{EBT}\left(\mathrm{X}_{1}\right)-0.258 \mathrm{BT}\left(\mathrm{X}_{2}\right)+0.013 \mathrm{GST}\left(\mathrm{X}_{3}\right)+6.954 \mathbf{N}$ $\operatorname{OPAT}\left(\mathrm{X}_{4}\right)+0.105 \mathrm{EI}\left(\mathrm{X}_{5}\right)$.

3. The calculated correlation value for the equation expressed above is 0.952 according to its Eigenvalues (9.667) and calculated $\mathrm{Chi}^{2}$ value (4356.61)

\section{Recommendation}

1. Base on the variables evaluated; it is important to classify the enterprises in the country base on financial indicators considering that it highlights Business Tax $(B T)\left(\mathrm{X}_{2}\right)$, General Sales Tax $(\mathrm{GST})\left(\mathrm{X}_{3}\right)$, and Net Operating Profit after Tax (NOPAT) $\left(\mathrm{X}_{4}\right)$ and Free Cash Flow $(\mathrm{FCF})\left(\mathrm{X}_{5}\right)$. Moreover; these variables were statistically significant and highly correlated as expressed in the Eigenvalues. 
Citation: Lewis RI (2018) Classification of the Micro, Small, Medium and Large (MSMLE's) Enterprises in Belize, Based on the Free Cash Flow (FCF). J Bus Fin Aff 7: 350. doi: 10.4172/2167-0234.1000350

Page 4 of 4

\begin{tabular}{|c|c|c|c|c|c|c|}
\hline & \multirow[b]{2}{*}{ Estimated Free cash Flow (FCF) Range? } & \multicolumn{4}{|c|}{ Predicted Group Membership } & \multirow[b]{2}{*}{ Total } \\
\hline & & 1569 TO 7689154 & 7689155 TO 15376139 & 15376740 TO 23064325 & 23064326 TO 30751911 & \\
\hline \multirow[t]{5}{*}{ Original Count } & 1569 TO 7689154 & 1374 & 17 & 0 & 0 & 1391 \\
\hline & 7689155 TO 15376139 & 0 & 93 & 0 & 0 & 93 \\
\hline & 15376740 TO 23064325 & 0 & 1 & 2 & 0 & 3 \\
\hline & 23064326 TO 30751911 & 0 & $\underline{\theta}$ & 0 & 3 & 3 \\
\hline & Ungrouped Cases & 0 & 0 & 0 & 10 & 10 \\
\hline \multirow[t]{5}{*}{$\%$} & 1569 TO 7689154 & 98.8 & 1.2 & 0 & 0 & 100 \\
\hline & 7689155 TO 15376139 & 0 & 100 & 0 & 0 & 100 \\
\hline & 15376740 TO 23064325 & 0 & 33.3 & 66.7 & 0 & 100 \\
\hline & 23064326 TO 30751911 & 0 & 0 & 0 & 100 & 100 \\
\hline & Ungrouped Cases & 0 & 0 & 0 & 100 & 100 \\
\hline
\end{tabular}

Table 7: Classification summary.

2. Use the calculated Mathematical Equation for unstandardized values for Enterprise classification as estimated.

3. All municipalities should formalize the informal business sector; by extending a specific license to Mobile Informal Micro Enterprise (MIME's) that are doing street vending, which can be seen as an avenue to create illegal competition for business.

\section{References}

1. Boguslauskas V, Adlyte R (2010) Evaluation of criteria for the classification of enterprises. Eng Econ 21: 119-127.

2. Creswell JW (2011) Research design; qualitative, quantitative, and mixed methods approaches. (3rd ed), Sage Publication 4: 16-89.

3. Dumrauf G (2010) Corporate finance - a Latin American approach. (2nd ed), Buena Aries: Alfaomega, pp: 25-80.

4. George D, Mallery P (2014) IBM SPSS; statistics 21, step by step, A simple guide, and reference. (13th ed), Pearson Education Inc, pp: 282-295.

5. Hallberg K (2000) A market-oriented strategy for small and medium scale enterprises. International Finance Corporation (IFC), USA, pp: 1-23.

6. Harris EA (2010) You can be a successful business person; Micro, Small \& Medium Enterprises (MSME's) Fundamentals. (2nd ed), USA.

7. Helfert EA (2001) Financial analysis tools and techniques: A guide for managers. (1st ed), McGraw-Hill, USA, pp: 15-58.

8. Herrle E (2006) The promotion of small and medium-sized Enterprises in the
EU. (1st Ed), Germany, pp: 1-23.

9. Malhorta M, Chen Y, Criscuolo A, Fan O, Hamel II, et al. (2007) Expanding access to finance, good practices and policies for micro, small and medium enterprises. (1st ed), The World Bank, Washington, DC, pp: 3-25.

10. Ross SA, Westfield WR, Jaffe J (2010) Cooperate finance. (9th ed), McGrawHill, USA, pp: 300-426.

11. Seepersaud MM (2012) Belize MSME policy and strategy report. Belize, pp: 5-61.

12. Sivakumar V (2010) Globalization of entrepreneurship: Overwhelming institutional response for SMEs in India. Ashland University.

13. Pooja K (2009) Micro, small and medium enterprise.

14. Tri Rahayu SA (2010) Analysis of investment decision in micro, small and medium enterprise (MSME's) in Indonesia.

15. Tambunan $T$ (2005) Promoting small and medium enterprises with a clustering approach: A policy experience from Indonesia. J Small Bus Manage 43: 138154.

16. Vintila G, Ghenghina SC (2014) Pattern recognition techniques to classify the European markets companies from the valuation perspective. Econ Comput Econ Cybern Stud Res 48: 1-17.

17. Warner RM (2012) Applied statistics: From bivariate through multivariate techniques. (2nd ed), Sage Publication Inc, pp: 51-59.

18. Yutaka Y (2011) Industrial clusters and micro \& small enterprises in Africa from survival to growth. (1st ed), The International Bank for Reconstruction and Development, World Bank, USA 1: 41-95. 